\title{
Purulent pericarditis: subdiaphragmatic suppurative focus
}

\author{
Kang-Un Choi ${ }^{1}$, Chan-Hee Lee ${ }^{2}$ \\ ${ }^{1}$ Division of Cardiology, Department of Internal Medicine, Dongguk University, Gyeongju Hospital, Gyeongju, Korea \\ ${ }^{2}$ Division of Cardiology, Department of Internal Medicine, Yeungnam University College of Medicine, Daegu, Korea
}

Received: May 29, 2019

Revised: August 16, 2019

Accepted: August 26, 2019

Corresponding author:

Chan-Hee Lee

Division of Cardiology, Department

of Internal Medicine, Yeungnam

University College of Medicine, 170

Hyunchoong-ro, Nam-gu, Daegu

42415, Korea

Tel: +82-53-620-3313

Fax: +82-53-621-3310

E-mail: chanheebox@naver.com
Purulent pericarditis is defined as a localized pericardial infection with gross pus formation in the pericardial space. Although purulent pericarditis is now rare in the antibiotic era, it may be life-threatening. We describe a rare case of purulent pericarditis that originated from a subdiaphragmatic suppurative focus in an immunocompromised host.

Keywords: Colorectal cancer; Escherichia coli; Pericarditis; Suppuration

\section{Introduction}

Purulent pericarditis is defined as a localized infection of the pericardial space characterized by gross pus formation in the pericardium. Although purulent pericarditis is now rare in the antibiotic era, if it is not diagnosed quickly, it may be life-threatening. We describe a rare case of purulent pericarditis that originated from a subdiaphragmatic suppurative focus in an immunocompromised host.

\section{Case}

A 53-year-old man was admitted to the emergency department with drowsiness. He was a heavy alcoholic and had a past medical history of diabetes and chronic hepatitis $\mathrm{C}(\mathrm{CHC})$. One month previously, he underwent surgery for peritonitis, which was related to a suspected perforation of a sigmoid colon diverticulum. The surgeon performed a segmental resection of the sigmoid co- lon, but could not detect any definite perforation site during the operation. The initial blood pressure was $80 / 50 \mathrm{mmHg}$, and body temperature $36^{\circ} \mathrm{C}$. The laboratory findings revealed a white blood cell (WBC) count of $13,980 / \mu \mathrm{L}$, hemoglobin of $7.8 \mathrm{~g} / \mathrm{dL}$, platelet count of $214 \mathrm{~K} / \mu \mathrm{L}$, and elevated creatinine of $5.85 \mathrm{mg} / \mathrm{dL}$, C-reactive protein of $24.6 \mathrm{mg} / \mathrm{dL}$ (range, $<0.5 \mathrm{mg} / \mathrm{dL}$ ), and procalcitonin of $31.9 \mathrm{ng} / \mathrm{mL}$ (range, $<0.5 \mathrm{ng} / \mathrm{mL}$ ). An arterial blood gas analysis on a $2 \mathrm{~L} / \mathrm{min}$ oxygen supplement via a nasal cannula revealed the following: $\mathrm{pH} 7.371$, partial pressure of carbon dioxide of $16.8 \mathrm{mmHg}$, partial pressure of oxygen $189 \mathrm{mmHg}, \mathrm{HCO}_{3}^{-} 9.5$ $\mathrm{mmol} / \mathrm{L}$, and oxygen saturation $99.5 \%$. A chest X-ray revealed an enlarged cardiac silhouette with pulmonary edema (Fig. 1A). Non-contrast chest computed tomography (CT) revealed large pericardial and pleural effusions (Fig. 1B, 1C), and echocardiography revealed a large pericardial effusion with non-homogeneous echogenicity (Fig. 1D). In view of the septic condition, an emergency pericardiocentesis via a subxiphoid approach was performed with drainage $(500 \mathrm{~mL})$ of pus (Fig. 2). The patient's

Copyright@ 2020 Yeungnam University College of Medicine

This is an Open Access article distributed under the terms of the Creative Commons Attribution Non-Commercial License (http://creativecommons.org/licenses/by-nc/4.0/) which permits unrestricted non-commercial use, distribution, and reproduction in any medium, provided the original work is properly cited. 

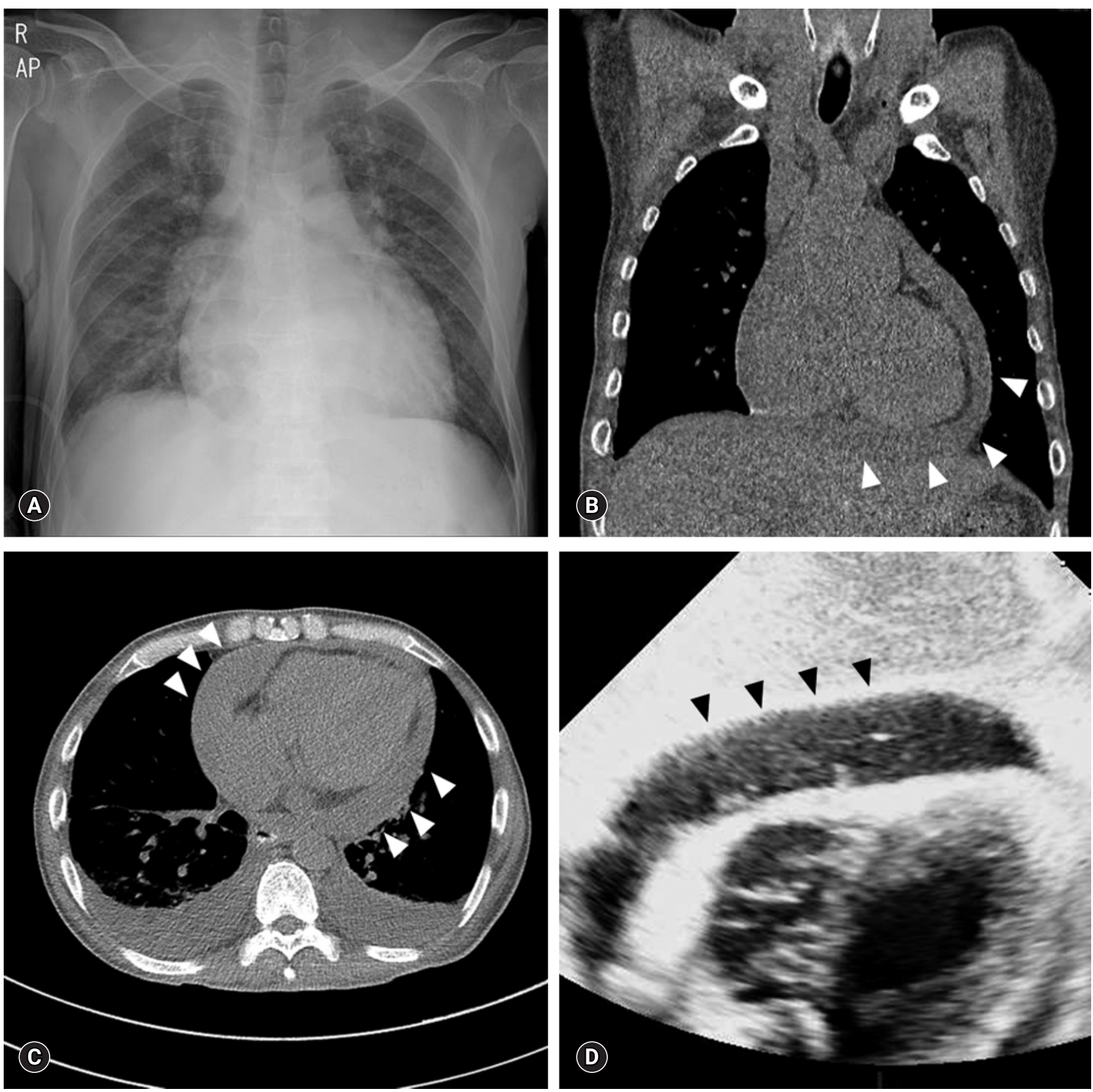

Fig. 1. (A) A chest $X$-ray shows an enlarged cardiac silhouette with pulmonary congestion. $(B, C) A$ non-contrast chest computed tomography reveals large pericardial (arrowheads) and pleural effusions ( $B$, coronal view; $C$, planar view). (D) The subxiphoid view of the echocardiography shows a large (about $2 \mathrm{~cm}$ ) pericardial effusion (arrowheads) with inhomogeneous echogenicity.

blood and pericardial fluid were collected for cultures and he was started on intravenous (IV) vancomycin and meropenem. The pericardial fluid analysis revealed a WBC count of $400,000 / \mu \mathrm{L}$ (polymorphonuclear leucocytes $65 \%$ ), glucose of $2 \mathrm{mg} / \mathrm{dL}$, adenosine deaminase of $270.5 \mathrm{IU} / \mathrm{L}$, and lactate dehydrogenase of 29,632 IU/L. A Gram stain of the pericardial fluid revealed
Gram-negative rods ( $>30$ per oil immersion field), and the acid-fast bacilli stain was negative. Cytology of the pericardial fluid was negative for the presence of atypical or malignant cells. On the 6th hospital day, the culture from the pericardial effusion grew extended-spectrum $\beta$-lactamase negative Escherichia coli. The blood cultures were negative. Follow-up echocardiography on the 
11th hospital day revealed a pericardial adhesion and thickening with a constrictive physiology (29\% respiratory variation of the mitral $\mathrm{E}$ wave velocity and septal bouncing motion).

His clinical symptoms and laboratory findings gradually improved with continuous renal replacement therapy, and IV meropenem was continued for 3 weeks. A contrast abdominal CT scan, performed on the 9th hospital day, showed a segmental wall thickening of the rectosigmoid junction with adjacent free air, which was suspected of being a rectal malignancy with a microperfora-

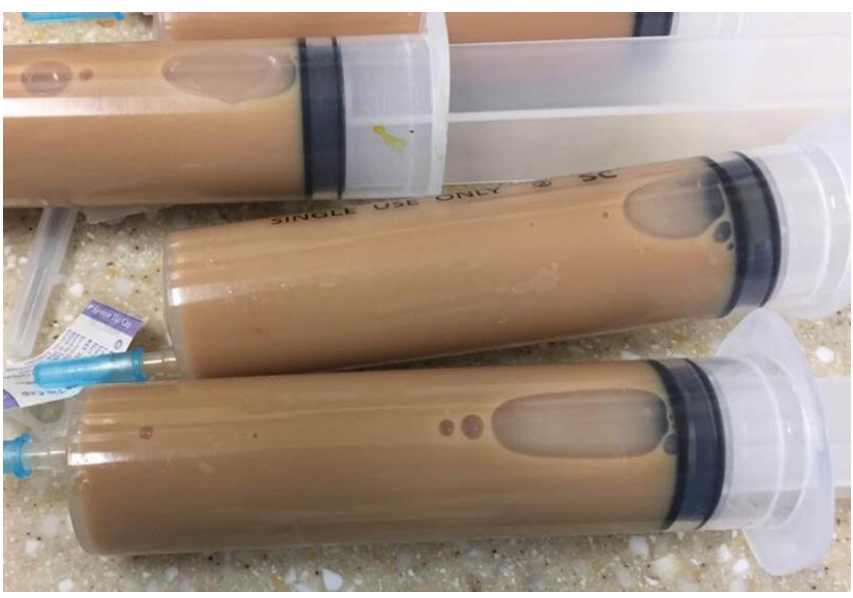

Fig. 2. Pericardial pus with a turbid yellowish brown color, which was drained via pericardiocentesis.
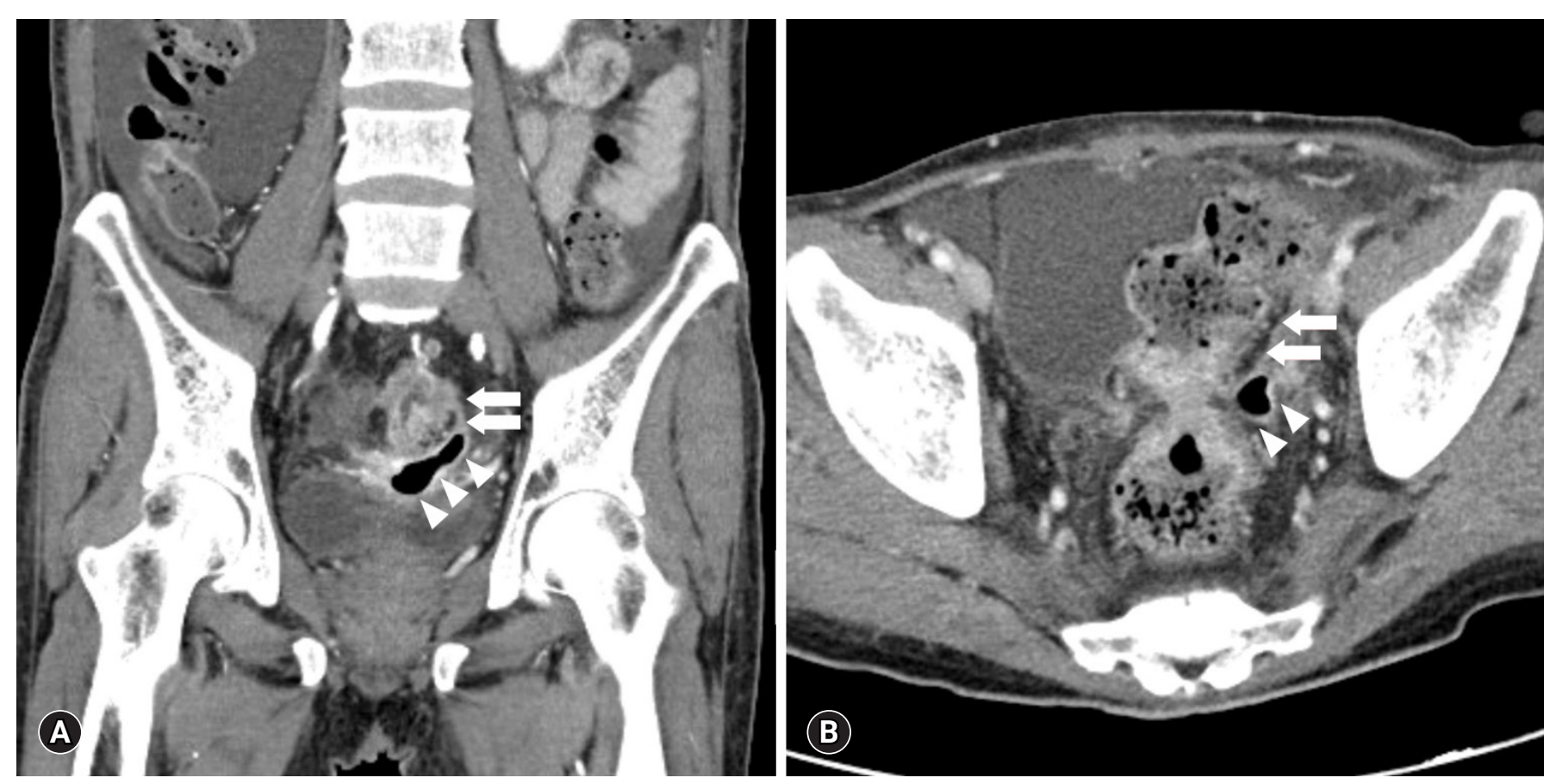

Fig. 3. The abdominal computed tomography ( $A$, coronal view; $B$, planar view) shows segmental wall thickening (arrows) of the rectosigmoid junction with adjacent free air (arrowheads).

tion (Fig. 3). The carcinoembryonic antigen level was $13.8 \mathrm{ng} /$ $\mathrm{mL}$ (range, $<10 \mathrm{ng} / \mathrm{mL}$ ). The fever subsided on the 9 th hospital day, and he was discharged without any abdominal symptoms on the 19th hospital day. He was transferred to the department of colorectal surgery, and underwent an open low anterior resection operation for rectosigmoid lesions. A direct invasion of the main colorectal mass into the adjacent tissue was detected during the operation, and a biopsy confirmed the adenocarcinoma. A follow-up echocardiography 6 months later revealed a slightly improved pericardial adhesion and thickening without an effusion.

\section{Discussion}

Purulent pericarditis is relatively uncommon in the antibiotic era, and occurs in less than $1 \%$ of patients presenting with acute pericarditis [1]. In the pre-antibiotic era, the major cause of purulent pericarditis was a primary infectious disease, such as pneumonia [2]. However, the predisposing factors have since changed to preexisting pericardial diseases, alcohol abuse, immunosuppression, surgery, and trauma [3]. Our patient was also an immunocompromised host with several predisposing factors such as alcohol abuse, diabetes, CHC, current abdominal surgery, and malignancy.

There are several mechanisms by which purulent pericarditis can develop: a direct spread of a thoracic infectious focus [4], hematogenous spread [5], and very rarely as an extension from a 
subdiaphragmatic suppurative focus [6]. Further, few strains of bacteria causing pericarditis have been identified. Streptococcal pneumonia [7] has been reported to be associated with respiratory infections or to occur after respiratory procedures. Purulent pericarditis caused by an intraperitoneal infection, such as Salmonella enteritis, has also been reported in an immunosuppressed host [8]. The purulent pericarditis in this patient was presumed to have developed due to bacterial seeding of a subdiaphragmatic focus, considering a current history of peritonitis surgery, pericardial fluid culture of E. coli, and colorectal malignancy with a suspected microperforation.

The cause of purulent pericarditis should also be considered to originate from a subphrenic focus if the patient has not had a recent respiratory tract infection. In this case, the Gram-negative strains could be covered by a broad spectrum antibiotic because the Gram stain was confirmed early. Therefore, a detailed medical history including one of recent infection needs to be elicited.

\section{Acknowledgments}

\section{Conflicts of interest}

No potential conflict of interest relevant to this article was reported.

\section{ORCID}

Kang-Un Choi, https://orcid.org/0000-0002-3385-3152

Chan-Hee Lee, https://orcid.org/0000-0001-9338-0679

\section{References}

1. Imazio M, Gaita F, LeWinter M. Evaluation and treatment of pericarditis: a systematic review. JAMA 2015;314:1498-506.

2. Klacsmann PG, Bulkley BH, Hutchins GM. The changed spectrum of purulent pericarditis: an 86 year autopsy experience in 200 patients. Am J Med 1977;63:666-73.

3. Adler Y, Charron P, Imazio M, Badano L, Barón-Esquivias G, Bogaert J, et al. 2015 ESC Guidelines for the diagnosis and management of pericardial diseases: The Task Force for the Diagnosis and Management of Pericardial Diseases of the European Society of Cardiology (ESC) Endorsed by: The European Association for Cardio-Thoracic Surgery (EACTS). Eur Heart J 2015;36: 2921-64.

4. Kauffman CA, Watanakunakorn C, Phair JP. Purulent pneumococcal pericarditis. A continuing problem in the antibiotic era. Am J Med 1973;54:743-50.

5. Boyle JD, Pearce ML, Guze LB. Purulent pericarditis: review of literature and report of eleven cases. Medicine 1961;40:119-44.

6. Ochsner A, DeBakey M. Subphrenic abscess: collective review and analysis of 3608 collected and personal cases. Int Abstr Surg $1938 ; 66: 426-38$.

7. Cillóniz C, Rangel E, Barlascini C, Piroddi IM, Torres A, Nicolini A. Streptococcus pneumoniae-associated pneumonia complicated by purulent pericarditis: case series. J Bras Pneumol 2015;41: 389-94.

8. Takamiya Y, Shirai K, Fujino M, Miller N, Tsuchiya Y, Okabe M, et al. Purulent pericarditis with Salmonella enteritidis in a patient with CD4/CD8 depression. J Cardiol 2008;51:201-4. 